\title{
A review on SARS-CoV2 drug regimens inferring plausible mechanisms to impede the viral propagation and cytokine storm
}

\author{
Poulomi Chatterjee, Niladri Prasad Mishra, Abhishek Das, Sagar Acharya*
}

Department of Zoology, Vidyasagar University, Midnapore, West Bengal, India

Received: 30 January 2021

Revised: 08 March 2021

Accepted: 09 March 2021

*Correspondence:

Dr. Sagar Acharya,

E-mail: sagar.gene@gmail.com

Copyright: (C) the author(s), publisher and licensee Medip Academy. This is an open-access article distributed under the terms of the Creative Commons Attribution Non-Commercial License, which permits unrestricted non-commercial use, distribution, and reproduction in any medium, provided the original work is properly cited.

\begin{abstract}
A sharp outbreak of pandemic severe acute respiratory syndrome coronavirus 2 (SARS-CoV2) in early 2020, has shaken up the whole global health care system and economy with its rapid chain-of-infection and high mortality index. This article emphasizes on the immunopathology of virus and current drug therapies. We have put down a compendious postulation on different drug actions vis-à-vis their reversing strategies for the pertinent diseases. A critical analysis has been made on the cytokine storm and focusing on to the interplays among lymphocytes and other innate immune cells (NK cells, macrophages, dendritic cells etc.) with secreted cytokines as well as on to the drug effectiveness by tallying with the contexts of SARS-CoV and Middle East respiratory syndrome coronavirus infections. The hustle and bustle is ongoing for repurposing existing drugs, designed for other infectious microbes. Tackling the adversities in anti-viral treatment has become too challenging to stop this contagion. Thereafter, the scientific front liners are on trials of hundreds of drugs by making comparisons to other contagious epidemics. Current review summarizes different drug actions on viral propagation and host immunomodulation. Our conjecture will intrigue to re-evaluate the mostly used drugs at present state.
\end{abstract}

Keywords: SARS-CoV2, Cytokine storm, Anti-viral drugs, Remdesivir, Favipiravir, Immunopathology

\section{INTRODUCTION}

In $21^{\text {st }}$ century, the deadly outbreak of newly emerged coronavirus disease 2019 (COVID-19) caused by severe acute respiratory syndrome coronavirus 2 (SARS-CoV2) is the third most lethal pathogenic human corona virus, after SARS-CoV and MERS-CoV in 2003 and 2012, respectively. ${ }^{1}$ The outbreak was first reported on December 31, 2019 in Wuhan City, Hubei Province, China. ${ }^{2}$ Originating from China, till now it has outspread nearly 215 countries including all major continents. On $26^{\text {th }}$ January 2021, globally above 98 million confirmed cases, and more than 2.1 million confirmed fatalities have been recorded (fatality rate of $2.15 \%$ worldwide). Fever $(83-98 \%)$, cough $(59-82 \%)$, shortness of breath (19-
$55 \%)$, and muscle ache (11-44\%) are the usual symptoms of SARS-CoV2 infection but some patients may develop sore throat, rhinorrhea, headache and fever, indicating as critical symptoms. ${ }^{2}$ When SARS-CoV2 progresses from severe to critical, patients may develop severe cytokine storm, secondary acute respiratory distress syndrome, followed by the shock, tissue perfusion disorders, and even multi-organ failure. ${ }^{2}$ Due to the high infectivity, mortality rate and the absence of definitive treatment protocols or therapeutic agents or vaccines, the urgency of this outbreak lead to the use of broad-spectrum clinically available non-specific antiviral drugs and nonviral drugs. In spite of significant efforts for the development of vaccines and therapeutic drugs none of them have reached to bedside. The vaccines which are 
came to light with promise and now under clinical trials but warrant more time. In some countries, several cocktail drugs or different combinational therapies are being used for the treatment of the SARS-CoV2 infected patients. Existing drugs that were previously designed for other specific viral infections are used to treat SARSCoV2 infection, and most of these agents were tested for their safety. Several clinical trials are in a row with different drugs, cocktails, and combinational therapies. These drugs either can be directly target the viral infection response pathways or boost host innate antiviral immune response or alleviate damage induced by dysregulated inflammatory responses. In the current context, we review the detail immunopathology of the infection with special emphasis to cytokine storm and the mechanism of different non-specific antiviral drugs used against SARS-CoV2 infection for the better therapeutic interventions against SARS-CoV2 infection. The review is also illustrating the world wide current status of the potential drugs used so far against the infection.

\section{PATHOLOGICAL ASPECTS OF SARS-COV2}

\section{Pathogenecity}

Recent understanding of the pathogenesis of SARS-CoV2 infection is still limited. Before 2019, there were six CoVs (HCoV-229E, HCoV-OC43, HCoV-NL63 and HCoV-HKU1) that could infect humans and cause respiratory disease i.e., the "common cold". ${ }^{3}$ Estimated $80 \%$ of the SARS-CoV2 infection is asymptomatic or mild, while remaining is severe or critical in condition. ${ }^{2}$ SARS-CoV2 can infect lower respiratory tract and causes severe pneumonia, which is similar to SARS-CoV and MERS-CoV, including fever, dry cough, dyspnea, myalgia, fatigue, normal or decreased leukocyte counts. ${ }^{4}$ Further SARS-CoV2 infection leads to lung inflammation, acute respiratory distress syndrome (ADRS), cardiac and renal injury and multi organ failure. ${ }^{4}$ Critical correlation with SARS-CoV and MERS$\mathrm{CoV}$ infection and information available for SARS-CoV2 infections so far will facilitate better clinical perception of the current pandemic.

\section{Immunopathology of SARS-COV2 infection}

SARS-CoV2 is mainly characterized by fever, pneumonia, lymphopenia, exhausted lymphocytes, lung inflammation and cytokine storm. ${ }^{5}$ SARS-CoV2 progress to ADRS approximately 8-9 days after symptom onset. ${ }^{2,4}$ The immunopathology of SARS-CoV2 infection closely resembles with SARS-CoV and MERS-CoV infection, which results an aggressive inflammatory responses and damage to the airways like alveolar cells, ciliated and goblet cells in the airways. ${ }^{5}$ Disease severity in patients is not only due to the viral infection but also the host response. ${ }^{4}$ The disease severity increase with age is also similar with SARS-CoV and MERS-CoV. ${ }^{2,4}$ Improved insight into immunopathological change in patient is important for better clinical management. The SARS-
CoV2 spike protein (S) is 20-30 amino acids longer than SARS-CoV and binds to the ACE-2 receptor over a host cell which includes human airway epithelial cells, goblet cells, type 2 alveolar epithelial cells, vascular endothelial cells, macrophages in the lung, cardiac cells and intestinal epithelium, all of which highly express the transmembrane ACE-2 receptor. ${ }^{5,6}$ The host response and clearance of viral infections heavily depends on type I interferon (IFN1) expression and programming the immune cells into an "anti-viral state".

Immune cells first identify the viral RNA through virus derived pathogen associated molecular patterns (PAMPs) which activate pattern recognition receptors (PRRs) resulting in the production of IFN1 and expression of IFN-stimulated genes (ISGs) that target viral life cycle, including virus binding to attachment receptors, virus entry, RNA synthesis, progeny virion assembly and egress. $^{8}$ As SARS-CoV, SARS-CoV2 can also be detected by endosomal RNA PRRs, toll-like receptors (TLR-)3,7/8, retinoic acid-inducible gene I (RIG-I) and melanoma differentiation- associated protein 5 (MDA5) (Figure 1). ${ }^{9}$ RIG-I and MDA5 can sense viral molecules in the cytoplasm ${ }^{10}$. Activated RIG-I (and MDA5) exposes its caspase activation and recruitment domains (CARD), which bind to the mitochondrial antiviral signaling (MAVS) protein to activate tank binding kinase 1 (TBK1) and I-kappa-B kinase $\varepsilon$ (IKK $\varepsilon$ ), leading to activation of transcription factors interferon regulatory factor (IRF) 3 and 7 results to production of IFN1 and as well as NFKB (Figure 1). ${ }^{8,10}$ The activated RIG-I binds to MAVS, leading to its prion like aggregation, where receptorinteracting serine-threonine kinase 1 (RIP1) and Fasassociated death domain (FADD) are involved for the initiation of NFKB pathway. ${ }^{8}$ Activation and nuclear translocation of interferon regulatory factor (IRF) $-3,-7$ and NFKB which leads to expression of IFN1 and proinflammatory cytokines (IL-1, IL-6, TNF- $\alpha$ ) (Figure 1). ${ }^{8,9}$ Similar to SARS-CoV, SARS-CoV2 may alter ubiquitination and degradation of RIG-I/ MDA5 and also inhibits activation of MAVS. ${ }^{11}$ SARS-CoV2 may also inhibit the TNF receptor-associated factors (TRAF) 3 and 6 in response to TLR3, 7/8 ligation and NFKB signaling pathway. ${ }^{11}$ SARS-CoV2 can counteract IFN1 signaling through the inhibition of STAT family transcription factor phosphorylation (Figure 1). ${ }^{8,9}$ The suppression of innate immune mechanisms in infected epithelial cells, monocytes and macrophages allow SARS-CoV2 to proliferate without activating the innate anti-viral response mechanism (Figure 1). ${ }^{8,9}$ Infected cells undergo cell death and released virus particles trigger innate inflammatory mechanisms through their recognition by PRRs on innate immune cells which result activation and expression of pro-inflammatory cytokines (including IL$1 \beta$, IL-6, TNF- $\alpha$, etc.). T lymphocytes play a crucial role in this anti-viral response, including CD4+ T cell derived cytokines, CD8+ T cell mediated cytotoxicity, and B cell activation resulting in antibody production (Figure 1). ${ }^{12}$ 


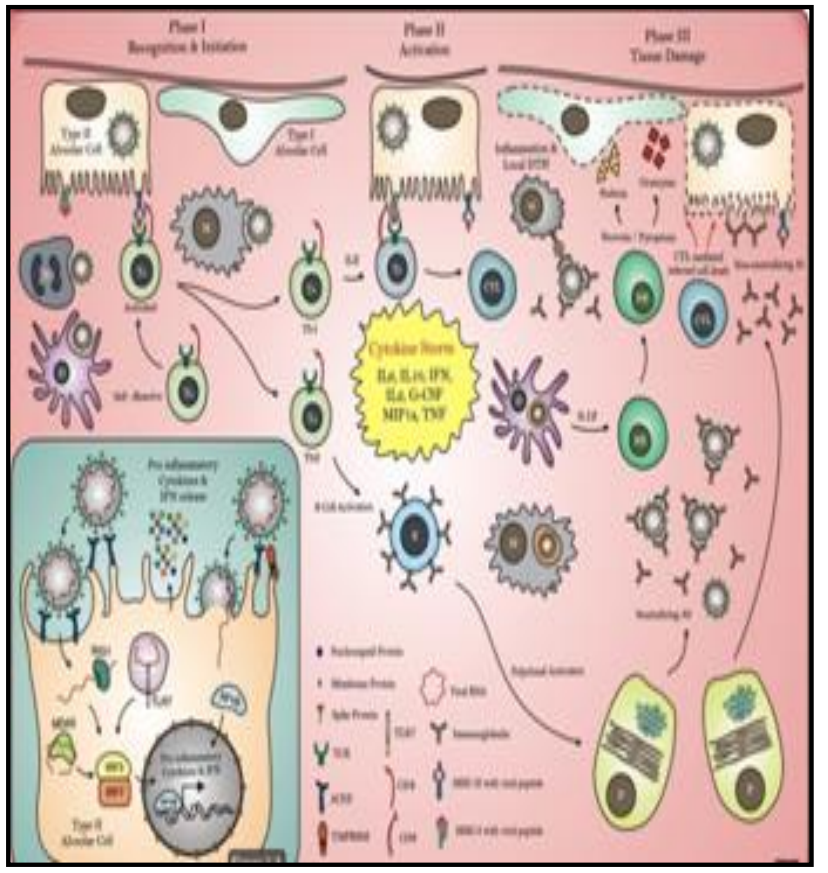

Figure 1: Immunopathology of SARS-CoV2 infection.

Pro-inflammatory cytokines and IFN genes are expressed via RIG-I, MDA5 and TLR mediated viral ssRNA sensing within type-II pneumocytes of infected patient. A trilogy of inflammatory Phase I (recognition and initiation): $T_{H}$ cell recognizes viral antigen and differentiate into Th1 and Th2 cells. Phase II (activation): Th1 cells trigger CTL, Th2 cells help in

B-cells maturation \& production of abs. Cytokine storm arises due to abnormal levels of cytokine secretion. Phase III (tissue damage): inflammation and local delayed type hypersensitivity.

The tissue injuries caused by the virus induce the production of pro-inflammatory cytokines, macrophages and granulocytes. Numerous studies have described abnormal levels of the cytokines and chemokines (IL-1, IL-2, IL-4, IL-6, IL-7, IL-10, IL-12, IL-13, IL-17，MCSF, G-CSF, GM-CSF, IP-10, IFN- $\gamma$, MCP-1, MIP 1- $\alpha$, hepatocyte growth factor (HGF), TNF- $\alpha$, and vascular endothelial growth factor (VEGF), CXCL10, CXCL8, CXCL9, CCL2, CCL3, CCL5) present in SARS-CoV2 infected patients. ${ }^{2,5,8,9}$ These results in the 'cytokine storm' termed as 'macrophage activation syndrome' or 'secondary hemophagocytic lymphohistiocytosis (HLH)' which leads to further tissue damage and multi-organ failure, including ADRS (Figure 1B)., ${ }^{2,4}$

At this juncture overreaction from the immune system can endanger a patient's life. Chemokines, opsonize professional microbe like neutrophils at the site of infections. Higher IL-1a and IL 4 levels in severe SARS$\mathrm{CoV} 2$ patients are strongly associated with lung injury. ${ }^{5}$

Cytokines such as interleukin 1b, interleukin 6 and tumor necrosis factor steer neutrophils and other immunocytes from blood capillaries to the site of infection. This recruited monocytes, macrophages and neutrophils to the site of infection, which exhibited strong and poorly controlled inflammatory responses, resulting the tissue damage and systemic inflammation and contribute to morbidity. ${ }^{13}$ A number of systemic inflammatory conditions and uncontrolled activation of immune responses is not limited to the innate mechanisms. As a result of pro-inflammatory cytokine expression and the presence of nuclear antigens, adaptive immune cells become activated and trigger a "second wave" of inflammation. 8,9

Finally, severely ill SARS-CoV2 infected patients are experiencing lymphopenia and atrophy of the lymph nodes and spleen. ${ }^{2,4}$ Primary and secondary forms of HLH and associated cytokine storm result in inflammatory cell death and hypo-cellularity of lymphatic organs. ${ }^{14}$ IL-6 in patients show accelerated inflammatory process, contributing to the cytokine storm and worsening the prognosis which is associated with cardiac damage in these patients. ${ }^{4,5}$

Elevated liver enzymes and creatinine seen in some SARS-CoV2 infected patients without respiratory failure, suggesting that the inflammatory cytokine storm is the cause of damage to extra-pulmonary tissues and organs., ${ }^{4,5}$ These cytokines can augment heartbeat, elevate body temperature, trigger blood clots that trap the pathogen and modulate body temperature, fever, weight loss and other physiological responses that have evolved to kill the virus. ${ }^{2,4,5}$ However, a crucial role seems to be played by IL-6, whose increased levels in the serum have been correlated with respiratory failure, ARDS, and adverse clinical outcomes. ${ }^{2,4,5}$

\section{TREATMENT WITH DRUGS}

The rapidity of pandemic SARS-CoV2 infection with concordant severe mortality rate gets going for an antidote or an authentic therapeutic strategy to stop this chain-infection. In 2003, the minimal severity of SARS$\mathrm{CoV}$ and in 2012, the epidemic emergence of MERS$\mathrm{CoV}$ had already led the scientific experts in generating vaccines which might be effective for SARS-CoV2 in the context of their sameness. ${ }^{1,2}$ Taxonomical parities with related virions and the symptomatic mimicries of SARS$\mathrm{CoV} 2$ with other contagious diseases clued the clinicians for miscellaneous drug usage. Manifold methodologies of a particular type of drug or concoctions of drugs have been used by the medical front-liners, unintendedly. Amongst all extensively used drugs, those which have shown substantial results are enlisted here with plausible mechanism of actions.

\section{Molecular mechanism of viral RNA-dependent RNA polymerase inhibitors}

Remdesivir, Favipiravir and Ribavirin act as nucleotide analogs to inhibit the viral RNA-dependent RNA polymerase (RdRp) during viral replication through competitive inhibition and/or chain termination (Figure 2). ${ }^{15}$ 


\section{Remdesivir (RDV, GS-5734)}

It is a novel antiviral nucleotide analogue developed by Gilead sciences, for the treatment of Ebola virus disease and Marburg virus infections. It has broad-spectrum in vitro activity against different RNA viruses such as Ebola virus, MERS-CoV, SARS-CoV, Nipah virus and Hendra virus. The anti-MERS-CoV activity of RDV is likely through premature termination of viral RNA transcription and has shown prophylactic and therapeutic efficacy in nonclinical models of these two coronaviruses. ${ }^{16}$

Experiments on enzyme kinetics revealed that whenever RDV, the adenosine tri-phosphate (ATP) analogue, was added into growing RNA chain, the reaction stopped after certain time period as this inhibitor caused chain termination after adding three or more ribo-nucleotides into it. ${ }^{17}$ Quantitative analyses have determined earlier that the Michaelis Menten parameters $\left(\mathrm{V}_{\max } / \mathrm{K}_{\mathrm{m}}\right)$ in this competitive inhibition by RDV, is highly significant to understand its efficiency of incorporation rate into viral genome, in comparison to competitor substrate ATP. ${ }^{17}$ The lastly added additional three nucleotides on growing chain following RDV help it from the exonucleoytic digestion ( $3^{\prime}$ to $5^{\prime}$ ) to which it is more sensitive. ${ }^{15}$ So, it could be a novel strategy for repurposing RDV against RNA virus like SARS-CoV2.

\section{Favipiravir (FAV, T-705)}

Favipiravir (6-fluoro-3-hydroxy-2-pyrazinecarboxamide, Fujifilm Toyama Chemical Co. Ltd, Tokyo, Japan) is selectively potent RdRp inhibitor against all serotypes and strains of influenza A, B and C virus and many other RNA viruses. Favipiravir performs by getting transformed into its most active form, Favipiravirribofuranosyl-5'-triphosphate (FRTP), after entering into the cell. ${ }^{18} \mathrm{~A}$ hypothesis on the functional property of FRTP explained that it might be mis-incorporated in a nascent growing RNA chain, otherwise the RdRp could be blocked (FRTP; $\mathrm{IC}_{50}$ of $0.341 \mu \mathrm{mol} / 1$ for influenza viruses) by binding to this guanosine triphosphate (GTP) analogue during viral RNA replication and transcription. ${ }^{18}$ Indeed, this binding site of FRTP on RdRp is conserved in RNA viruses and it is unable to block human DNA polymerases $(\alpha, \beta$ and $\gamma)$ up to $\mathrm{IC}_{50}$ of $1000 \mu \mathrm{mol} / 1$ and slightly blocks human RNA polymerase II, at an $\mathrm{IC}_{50}$ of $905 \mu \mathrm{mol} / \mathrm{l}^{18}$

FRTP introduces lethal mutagenesis of various nucleoprotein clones by generating identifiable transition mutations ( $\mathrm{G}$ to $\mathrm{A}$ and $\mathrm{C}$ to $\mathrm{T}$ or $\mathrm{C}$ to $\mathrm{U}$ ) and transversions with almost no viable drug resistant mutants. ${ }^{18}$ Another line of evidence has shown that the single molecular addition of FRTP only can prevent the RNA chain extension and double incorporation leads to complete stoppage of any further extension. ${ }^{19}$ Thereafter, this mechanism of action might delineate favipiravir as a serious virucidal substance against SARS-CoV2.

\section{Ribavirin (RBV)}

Ribavirin (tribavirin) is used against respiratory syncytial virus, hepatitis C, lassa fever, Crimean-Congo hemorrhagic fever, Venezuelan hemorrhagic fever and Hanta virus. It is on the world health organization's list of essential medicines as the safest and most effective medicine for human health and was patented in 1971 and approved for medical use in 1986. Ribavirin, a guanosine analogue, inhibits ionosine monophosphate dehydrogenase (IMPDH) by getting into singly phosphorylated form i.e. ribavirin monophosphate (RMP) and then to triple phosphorylated state: RTP. RMP inhibits IMPDH driven GTP synthesis and that low levels of the cellular GTP, accelerates the incorporation of Ribavirin by viral RdRp, as a mutagenic GTP-analogue into the growing RNA. Scarcity in guanosine also may hamper with $5^{\prime}$-guanosine cap formation, and naturally this uncapped viral RNA is prone to degradation by RNase. Some studies indicated that the Th1 cell polarization is enhanced by Ribavirin during T-cell regulated anti-viral response. ${ }^{20}$ By inhibiting RdRp, Ribavirin may destabilize the nascent viral RNA and thus it might block the chain extension which needs further studies emphasizing on drug action.

\section{Molecular mechanism of viral entry inhibitor/immune- modulator}

Hydroxychloroquine (HCQ) and chloroquine (CQ); HCQ and CQ both are potent anti-malarial drugs and show immunomodulatory effects in autoimmune conditions (rheumatoid arthritis and systemic lupus erythematosus) by mediating anti-inflammatory responses. CQ was first developed in 1934 and HCQ in 1955.

Glycosylation inhibition might be a major ruse of CQ for blocking the pre-entry step of virus into host cell. Interplay between $\mathrm{CQ}$ and glycosyl-transferases may occur within human cells as CQ has shown to inhibit quinine reductase 2, a structural neighbor of UDP-Nacetyl-glucosamine 2-epimerases, involved in sialic acid biosynthesis. The sialic acids are present at the extremity of ACE2 (expressed in lung, heart, kidney and intestine). ${ }^{21} \mathrm{CQ}$ derivatives by reducing $\mathrm{N}$-terminal glycosylation on ACE2 receptor may change the property of ACE2's ligand binding site for S1 spike protein on virus envelope and consequently the viral ingression might become hindered (Figure 2). ${ }^{21}$

HCQ and CQ are accumulated in lysosomes by lysosomotropism and interfere in its enzymatic activity which rapidly onsets the immunomodulatory or antiinflammatory consequences (Figure 3). CQ derivatives briskly increase the organellar $\mathrm{pH}$ of lysosome just after its entry into the alveolar type II cells which lead to inhibition of hydrolytic enzymes and normal degradation of cargo, hindering MHC-II mediated presentation. ${ }^{22}$ Sudden rise in $\mathrm{pH}$ impairs processing of endosomal TLRs (TLR7, TLR8, TLR9). CQ and HCQ interfere with 
TLR7-RNA interactions by directly binding to nucleic acid and can inhibit RNA-mediated TLR7 signaling. ${ }^{24}$ (Figure 3). ${ }^{23}$ Hereafter this hampered TLR signaling might be a cause of drug effectiveness in a COVID-19 patient. ${ }^{25} \mathrm{HCQ} / \mathrm{CQ}$ blocks the binding of cytosolic RNA with cyclic-GMP-AMP synthase (cGAS) (Figure 3). ${ }^{26}$ Cytosolic cGAS-STING complex captures cytosolic RNA and then concerts the transcription of IFN1 gene (IFN $\beta$, IL-6, IL-12 etc.). ${ }^{26}$ SARS-CoV RNA is able to bind with cGAS and induces cGAS-STING pathway and SARSCoV2 is robustly responsive to IFN1, thereafter, this CQ/HCQ might abrogate the pro-inflammatory cytokine release due to anti-viral response..$^{23,25}$

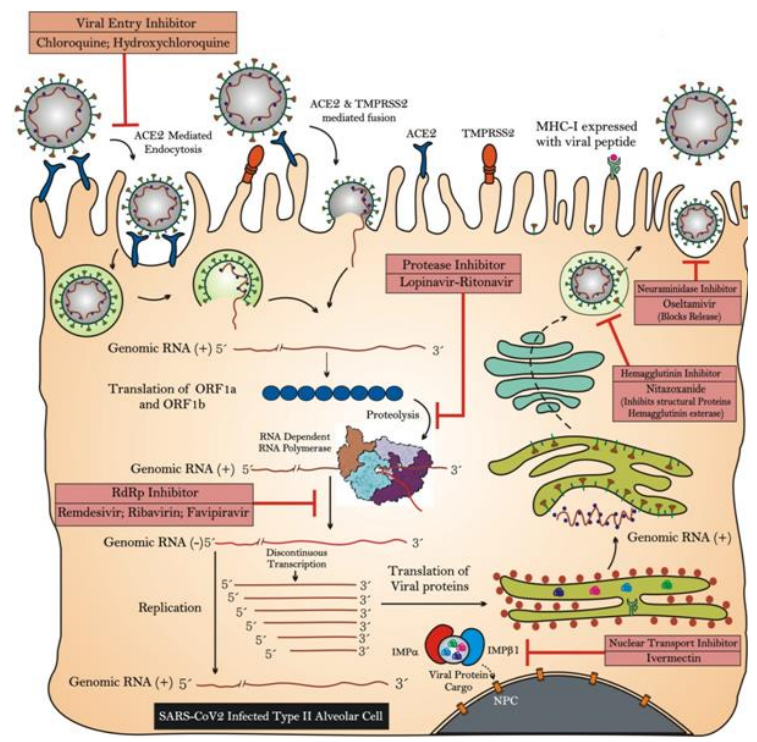

Figure 2: Schematic depicting drug activity at different stages of SARS-CoV2 life-cycle. CQ and HCQ block TMPRSS2 and ACE2 mediated endocytosis of SARS-CoV2. LPV \& RTV block proteolytic cleavage of relicase poly-proteins by $3 \mathrm{CL}$ protease. RDV, RBV \& FAV block the function of

RTC by binding with RdRp. IVT is a blocker of nuclear shuttling of viral protein cargo via Importin $\alpha / \beta 1$ through NPC. NZX hampers in the posttranslational modification and packaging of hemagglutinin esterase protein. OTV prevents the release of virion replica from host cell.

\section{Molecular mechanism of different immune-suppressive drugs}

Jakinibis (Baricitinib and Ruxolitinib); baricitinib was first used in February, 2017, in European union as a second-line medication for moderate to severe rheumatoid arthritis in adults. Later on April, 2018, this drug got an approval from FDA advisory committee. It acts as an inhibitor of JAK1 and JAK2 janus kinase subtypes. Ruxolitinib also acts an inhibitor of JAK1 and JAK2 and is used for the treatment of myelofibrosis and polycythrmia vera. In November 2011, it was approved by USFDA for the usage in intermediate to high risk myelofibrosis.
Jakinibs (JAK-inhibitors) are the type of drug that performs in auto-immune state of immune response by blocking the JAK activation by trans-phosphorylation on heterodimeric interferon receptor (IFNAR) in virus infected cells (Figure 3). ${ }^{27}$ Baricitinib and ruxolitinib are clinically moderately used jakinibs in SARS-CoV2 mediated viral infection. ${ }^{28}$ In normal antiviral response of natural killer (NK) cells and macrophages, proinflammatory cytokines (IL-1, IL-6 etc.) are released and myeloid cells (including dendritic cells) overproduces IFN1s which lead to activation of regulatory $\mathrm{T}$ cells and B cells. ${ }^{29}$ These two drugs are known for their firstgeneration competitive inhibition reaction kinetics where they compete with ATP to bind at the JH1 Tyrosine kinase domain on JAK molecule in its active form. ${ }^{29}$ In downstream signaling of JAK-STAT pathway, the active phosphorylated dimer of STAT molecule regulates the IFN gene signature which promotes the IFN autoinflammatory loop (Figure 3 ). ${ }^{29}$

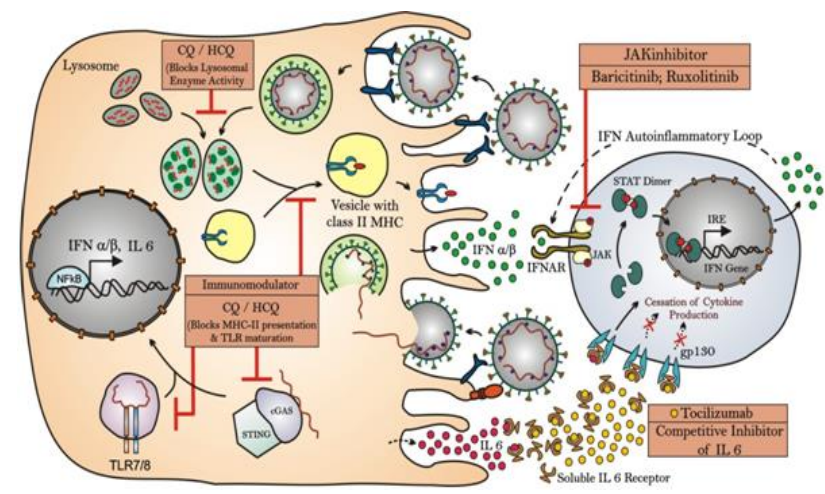

Figure 3: Illustration of immunomodulatory and immunosuppressive antiviral drugs. CQ/HCQ accumulates into lysosome and increases the lysosomal pH. CQ derivatives block the viral RNA binding to cGAS-STING complex and to endosomal TLRs which are involved into IFN1 gene expression. Jakinibs inhibit JAK-STAT signaling pathway by blocking the trans-phosphorylation of JAKs leading to cessation of IFN gene expression and the IFN autoinflammatory loop is paused. TCZ (competitive inhibitor of IL6) binds to soluble \& membrane bound

IL-6 receptors \& blocks the cis \& trans signaling pathway mediated by gp 130 subunits.

The Jakinibs act by blocking the trans-phosphorylation of JAKs on IFNAR which leads to inactivation of STAT molecules. As a result the IFN auto-inflammatory loop becomes hampered. ${ }^{27}$ Hereafter, by dampening the proinflammatory cytokine synthesis jakinibs might block the anti-viral response in a COVID-19 patient.

\section{Tocilizumab (TCZ)}

Tocilizumab (atlizumab) is a humanized monoclonal antibody against interleukin-6 receptor (IL-6R) and was developed by Hoffmann-La Roche and Chugai. It is used as an immunosuppressive agent for treatment of mainly 
rheumatoid arthritis and systemic juvenile idiopathic arthritis and later approved for Castleman's disease, neuromyelitis optica, giant cell arteritis, cytokine release syndrome like autoimmune disorders.

Tocilizumab has shown noticeable effectiveness against SARS-COV2. ${ }^{30}$ Strategy for this drug is to block the IL6$\mathrm{R}$ from binding with IL-6, through competitive inhibition (Figure 3). ${ }^{30}$ Tocilizumab binds to soluble and membrane bound IL-6R and then blocks the cis and trans signaling by glycoprotein 130 (gp130) subunits. $^{30}$ Hence, the SARS-CoV2 induced cytokine storm might be shattered to some extent, although there is not sufficient information on how this drug functions to block the infection.

\section{Molecular mechanism of neuraminidase inhibitor}

Viral neuraminidases are a category of enzyme found on the capsid surface of Influenza viruses. They cleave the terminal sialic acid moiety on host membrane glycoprotein to get escaped from the budding state in host cell to a free virion for further propagation.

\section{Oseltamivir (OTV, GS-4104)}

Oseltamivir (Tamiflu) is an orally administered antiviral drug used for the treatment of influenza A and B.

It is used as a prodrug (phosphate) of neuraminidase inhibitors against influenza like symptoms and after administration it is converted into active carboxylate form by hepatic esterases in host body. ${ }^{31}$ The active form binds to and inhibits the active site of the neuraminidase enzymes which exist on all influenza viruses and crucial for the release of the progeny virus from infected cells (Figure 2) ${ }^{31}$ In case of SARS-CoV2, this neuraminidase glycoprotein inhibitor might have subtle approach of inhibition towards virus $\mathrm{S} 1$ (spike) protein which has high sequence similarity with $\mathrm{H}_{1} \mathrm{~N}_{1}$ neuraminidase segment and NS1/NS2 virulence factors. ${ }^{32}$ This could be the mechanism of oseltamivir in restricting SARS-CoV2 propagation within host.

\section{Molecular mechanism of hemagglutinin inhibitor}

\section{Nitazoxanide $(N Z X)$}

Nitazoxanide or 2-(acetyloxy)-N-(5-nitro-2-thiazolyl) benzamide which was first synthesized in the early 1970 s as an oral anti-parasitic agent, has been extensively commercialized in India as a broad-spectrum antiparasitic drug for the treatment of intestinal infections by Cryptosporidium parvum and Giardia lamblia. It is also effective for anti-helminth, anti-protozoan, anti-viral and anti-cancer treatments. This drug is effective in blocking the maturation of viral hemagglutinin at its posttranslational stage (Figure 2). ${ }^{33}$ SARS-COV2 has a hemagglutinin esterase protein in its surface and this drug may block the packaging of this structural protein inside infected host cell. Therefore, with this defective hemagglutinin protein, the virus could not be able to get its infectious form back.

\section{Molecular mechanism of nuclear transport inhibitor}

Ivermectin (IVT)

Ivermectin is an anti-parasitic drug for head lice, scabies, river blindness, strongyloidiasis, trichuriasis, ascariasis and lymphatic filariasis. In vitro studies of Ivermectin on SARS-CoV2 infection have shown satisfactory evidences on blocking the enhanced antiviral responses. ${ }^{34}$ The molecular pathway of blocking relies upon Importin $\alpha / \beta 1$ mediated cytoplasmic transportation of molecular cargo into nucleus through nuclear pore complex (Figure 2). ${ }^{35,36}$ Ivermectin binds to Importin heterodimer and may prevent its signaldependent nucleo-cytoplasmic shuttling of viral nucleocapsid protein cargo and simultaneously might block the host cell's antiviral response. ${ }^{37}$

\section{Molecular mechanism of viral protease inhibitors}

\section{Lopinavir $(L P V) /$ ritonavir $(R T V)$}

LPV-RTV is the most clinically favored anti-retroviral, dual-drug regimen for SARS-CoV2 treatment, used all over the world and was first developed as an inhibitor of HIV-1 protease. ${ }^{38,39}$ LPV is a novel protease inhibitor which is derived from RTV and is same in their mechanism of action. ${ }^{40,41}$ SARS-COV2 main protease, $3 \mathrm{CL}^{\mathrm{PRO}}$ plays a major role in proteolytic cleavage of replicase polyproteins which is definite important in forming the core structure of Replication Transcription Complex (RTC) during viral replication (Figure 2). ${ }^{42,43}$ The molecular interactions like hydrogen bond, electrostatic and van der Waals interactions might occur in between the active site of SARS-CoV2 3CL conserved domain and the drug which may hamper the proteolysis of replicase polyproteins. ${ }^{42}$ Subsequently, the viral maturation may become arrested and the nascent virion might loss its infectivity.

\section{OTHER TREATMENT STRATEGIES}

Convalescent plasma therapy and monoclonal antibody therapy are other two prominent therapies against SARSCov-2. In the first case, the serum was separated from the collected blood sample of a person who had just got recovery from infection and the serum which contains antibodies was injected into a newly infected person to directly activate the immune response. ${ }^{44,45}$ It has been reported that this plasma transfusion might be beneficial to critically ill COVID19 patients. ${ }^{46}$ Existing risk factors of serum disease and antibody-dependent enhancement of infection, associated with sera transfusion enhanced the urgency of monoclonal antibody therapy. ${ }^{47}$ As SARSCoV-2 enters into the host cell by using the ACE2 
receptor for entry and the TMPRSS2 serine protease for $\mathrm{S}$ protein priming, an anti-S1 human monoclonal antibody has shown its competency against the virus. ${ }^{48}$ Research reports have declared that monoclonal antibodies, such as CR3022, 47D11 (human) can be used as potential therapeutics to stop the course of virus or to immunize an uninfected host that is supposed to get viral exposure. ${ }^{46,49,50}$

\section{CONCLUSION}

On the cusp of 2020, we, the humankind start to grapple with a stronghold global force, namely COVID-19. This pandemic has emerged as a myriad challenge. Global pharmacopoeia with flimsy pretext of general anti-viral drugs exaggerates more insight into drug administration on COVID-19 patients. A groundswell of suspicion has developed regarding SARS-CoV2 pathogenecity, embodied with multiple organ failure. This all-hands-ondeck demands a streamlined technology to countermand this pandemic viral surge, immediately. Keeping abreast of diversified strategies for repurposing drug applications, here, we have reviewed some specific ones as per their worldwide consistent usage, for last few months since SARS-CoV2 emergence. These forefront drug therapies are merely scratching in unfolding the COVID19-enigma. Amongst all, remdesivir, favipiravir and tocilizumab are indefinitely close to combat the chain-infection. To date no such WHO-approved or comprehensible drug has been reported, although it is undeniable that different countries are "on track" of trials for forthcoming solution. Since the heady first days of SARS-CoV2, the Stepford experts are interweaving brew of drugs, technologies in search of an epitome one against it to hold up our indigenous territories of life on healthy mother earth.

Funding: No funding sources Conflict of interest: None declared

Ethical approval: Not required

\section{REFERENCES}

1. Zaki AM, Van Boheemen S, Bestebroer TM, Osterhaus AD, Fouchier RA. Isolation of a novel coronavirus from a man with pneumonia in Saudi Arabia. New Eng J Med. 2012;367(19):1814-20.

2. Huang C, Wang Y, Li X, Ren L, Zhao J, Hu Y, et al. Clinical features of patients infected with 2019 novel coronavirus in Wuhan, China. The lancet. 2020; 395(10223):497-506.

3. Su S, Wong G, Shi W, Liu J, Lai AC, Zhou J, et al. Epidemiology, genetic recombination, and pathogenesis of coronaviruses. Trends Microbiol. 2016;24(6):490-502.

4. Guan WJ, Ni ZY, Hu Y, Liang WH, Ou CQ, He JX, et al. Clinical characteristics of coronavirus disease 2019 in China. New Eng J Med. 2020;382(18):170820.

5. Wong CK, Lam CW, Wu AK, Ip WK, Lee NL, Chan $\mathrm{IH}$, et al. Plasma inflammatory cytokines and chemokines in severe acute respiratory syndrome. Clin Exp Immunol. 2004;136(1):95-103.

6. Xu H, Zhong L, Deng J, Peng J, Dan H, Zeng X, et al. High expression of ACE2 receptor of 2019-nCoV on the epithelial cells of oral mucosa. Int J Oral Sci. 2020;12(1):1-5.

7. Addi AB, Lefort A, Hua X, Libert F, Communi D, Ledent $\mathrm{C}$, et al. Modulation of murine dendritic cell function by adenine nucleotides and adenosine: involvement of the $\mathrm{A} 2 \mathrm{~B}$ receptor. Eur $\mathrm{J}$ Immunol. 2008;38(6):1610-20.

8. Ma DY, Suthar MS. Mechanisms of innate immune evasion in re-emerging RNA viruses. Current Opinion Virol. 2015;12:26-37.

9. Mazaleuskaya L, Veltrop R, Ikpeze N, Martin-Garcia J, Navas-Martin S. Protective role of Toll-like receptor 3-induced type $\mathrm{I}$ interferon in murine coronavirus infection of macrophages. Viruses. 2012; 4(5):901-23.

10. Chow KT, Gale JM, Loo YM. RIG-I and other RNA sensors in antiviral immunity. Ann Rev Immunol. 2018;36:667-94.

11. Kindler E, Thiel V, Weber F. Interaction of SARS and MERS coronaviruses with the antiviral interferon response. In: Advances in virus research. USA: Academic Press; 2016:96;219-43.

12. Ahmadpoor P, Rostaing L. Why the immune system fails to mount an adaptive immune response to a Covid-19 infection. Transplant Int. 2020;85:53-9.

13. Zhang W, Zhao Y, Zhang F, Wang Q, Li T, Liu Z, et al. The use of anti-inflammatory drugs in the treatment of people with severe coronavirus disease 2019 (COVID-19): The Perspectives of clinical immunologists from China. Clin Immunol. 2020; 25:108393.

14. Croker BA, O’Donnell JA, Gerlic M. Pyroptotic death storms and cytopenia. Curr Opinion Immunol. 2014;26:128-37.

15. Agostini ML, Andres EL, Sims AC, Graham RL, Sheahan TP, Lu X, et al. Coronavirus susceptibility to the antiviral remdesivir (GS-5734) is mediated by the viral polymerase and the proofreading exoribonuclease. MBio. 2018;9(2).

16. Jordan PC, Liu C, Raynaud P, Lo MK, Spiropoulou $\mathrm{CF}$, Symons JA, et al. Initiation, extension, and termination of RNA synthesis by a paramyxovirus polymerase. PLoS. 2018;14(2):e1006889.

17. Gordon CJ, Tchesnokov EP, Feng JY, Porter DP, Götte M. The antiviral compound remdesivir potently inhibits RNA-dependent RNA polymerase from Middle East respiratory syndrome coronavirus. J Biol Chem. 2020;295(15):4773-9.

18. Furuta Y, Gowen BB, Takahashi K, Shiraki K, Smee DF, Barnard DL. Favipiravir (T-705), a novel viral RNA polymerase inhibitor. Antiviral research. 2013; 100(2):446-54.

19. Sangawa H, Komeno T, Nishikawa H, Yoshida A, Takahashi K, Nomura N, et al. Mechanism of action of T-705 ribosyl triphosphate against influenza virus 
RNA polymerase. Antimicrobial agents and chemotherapy. 2013;57(11):5202-8.

20. Khalili JS, Zhu H, Mak NS, Yan Y, Zhu Y. Novel coronavirus treatment with ribavirin: Groundwork for an evaluation concerning COVID-19. Journal of medical virology. 2020;55:98-105.

21. Zhuang MW, Cheng Y, Zhang J, Jiang XM, Wang L, Deng $\mathbf{J}$, et al. Increasing host cellular receptorangiotensin-converting enzyme 2 (ace2) expression by coronavirus may facilitate 2019-nCoV (or SARS-CoV-2) Infection. J Med Virol. 2020;80:5967.

22. Ballabio A, Bonifacino JS. Lysosomes as dynamic regulators of cell and organismal homeostasis. Nature Rev Mol Cell Biol. 2019;2:1-8.

23. Schrezenmeier E, Dörner T. Mechanisms of action of hydroxychloroquine and chloroquine: implications for rheumatology. Nature Rev Rheumatol. 2020;16 (3):155-66.

24. Rokni M, Ghasemi V, Tavakoli Z. Immune responses and pathogenesis of SARS-CoV-2 during an outbreak in Iran: Comparison with SARS and MERS. Rev Med Virol. 2020;30(3):e2107.

25. Meyerowitz EA, Vannier AG, Friesen MG, Schoenfeld S, Gelfand JA, Callahan MV, et al. Rethinking the role of hydroxychloroquine in the treatment of COVID-19. The FASEB J. 2020;34(5): 6027-37.

26. Lokugamage KG, Hage A, Schindewolf C, Rajsbaum $\mathrm{R}$, Menachery VD. SARS-CoV-2 is sensitive to type I interferon pretreatment. BioRxiv. 2020;97:58-68.

27. Hoffman HM, Broderick L. JAK inhibitors in autoinflammation. J Clin Invest. 2018;128(7):276062.

28. Stebbing J, Phelan A, Griffin I, Tucker C, Oechsle O, Smith D, et al. COVID-19: combining antiviral and anti-inflammatory treatments. Lancet Infect Dis. 2020;20(4):400-2.

29. Virtanen AT, Haikarainen T, Raivola J, Silvennoinen O. Selective JAKinibs: prospects in inflammatory and autoimmune diseases. BioDrugs. 2019;33(1):1532.

30. Misra DP, Agarwal V, Gasparyan AY, Zimba O. Rheumatologists' perspective on coronavirus disease 19 (COVID-19) and potential therapeutic targets. Clin Rheumatol. 2020;39(7):2055-2.

31. He G, Massarella J, Ward P. Clinical pharmacokinetics of the prodrug oseltamivir and its active metabolite Ro 64-0802. Clin Pharm. 1999; 37(6):471-84.

32. Zhang XW, Yap YL. The 3D structure analysis of SARS-CoV S1 protein reveals a link to influenza virus neuraminidase and implications for drug and antibody discovery. J Mol Stru. 2004;681(1-3):137-1.

33. Rossignol JF, La Frazia S, Chiappa L, Ciucci A, Santoro MG. Thiazolides, a new class of antiinfluenza molecules targeting viral hemagglutinin at the post-translational level. J Biol Chem. 2009;284 (43):29798-808.
34. Nicolas P, Maia MF, Bassat Q, Kobylinski KC, Monteiro W, Rabinovich NR, et al. Safety of oral ivermectin during pregnancy: a systematic review and meta-analysis. Lancet Global Health. 2020;8(1):e92-100.

35. Wagstaff KM, Rawlinson SM, Hearps AC, Jans DA. An AlphaScreen ${ }^{\circledR}$-based assay for high-throughput screening for specific inhibitors of nuclear import. J Biomol Screen. 2011;16(2):192-200.

36. Wagstaff KM, Sivakumaran H, Heaton SM, Harrich $\mathrm{D}$, Jans DA. Ivermectin is a specific inhibitor of importin $\alpha / \beta$-mediated nuclear import able to inhibit replication of HIV-1 and dengue virus. Biochem J. 2012;443(3):851-6.

37. Wulan WN, Heydet D, Walker EJ, Gahan ME, Ghildyal R. Nucleocytoplasmic transport of nucleocapsid proteins of enveloped RNA viruses. Front Microbiol. 2015;6:553.

38. Wang Q, Zhao Y, Chen X, An H. Virtual screening of approved clinic drugs with main protease $(3 \mathrm{CL}$ pro) reveals potential inhibitory effects on SARSCoV-2. J Biol Chem. 2020;52:67-9.

39. Sham HL, Kempf DJ, Molla A, Marsh KC, Kumar GN, Chen CM, et al. ABT-378, a highly potent inhibitor of the human immunodeficiency virus protease. Antimicrob Agents Chemother. 1998;42 (12):3218-24.

40. Murphy RL, Brun S, Hicks C, Eron JJ, Gulick R, King M, et al. ABT-378/ritonavir plus stavudine and lamivudine for the treatment of antiretroviral-naive adults with HIV-1 infection: 48-week results. Aids. 2001;15(1):F1-9.

41. Cvetkovic RS, Goa KL. Lopinavir/ritonavir: A review of its use in the management of HIV infection. Drugs. 2003;63(8):769-2.

42. Nukoolkarn V, Lee VS, Malaisree M, Aruksakulwong O, Hannongbua S. Molecular dynamic simulations analysis of ritronavir and lopinavir as SARS-CoV 3CLpro inhibitors. J Theor Biol. 2008;254(4):861-7.

43. Anand K, Ziebuhr J, Wadhwani P, Mesters JR, Hilgenfeld R. Coronavirus main proteinase (3CLpro) structure: basis for design of anti-SARS drugs. Science. 2003;300(5626):1763-7.

44. Soo YO, Cheng Y, Wong R, Hui DS, Lee CK, Tsang $\mathrm{KK}$, et al. Retrospective comparison of convalescent plasma with continuing high-dose methylprednisolone treatment in SARS patients. Clinical microbiology and infection. 2004;10(7):6768.

45. Shen C, Wang Z, Zhao F, Yang Y, Li J, Yuan J, et al. Treatment of 5 critically ill patients with COVID-19 with convalescent plasma. JAMA. 2020;323(16):1582-9.

46. Kumar GV, Jeyanthi V, Ramakrishnan S. A short review on antibody therapy for COVID-19. New Microbes New Infect. 2020:100682.

47. Casadevall A, Pirofski LA. The convalescent sera option for containing COVID-19. The Journal of clinical investigation. 2020;130(4):1545-8. 
48. Hoffmann M, Kleine-Weber H, Schroeder S, Krüger $\mathrm{N}$, Herrler T, Erichsen S, et al. SARS-CoV-2 cell entry depends on ACE2 and TMPRSS2 and is blocked by a clinically proven protease inhibitor. Cell. 2020;45:87-95.

49. Tian X, Li C, Huang A, Xia S, Lu S, Shi Z, et al. Potent binding of 2019 novel coronavirus spike protein by a SARS coronavirus-specific human monoclonal antibody. Emerg Microbes Infec. 2020;9(1):382-5.
50. Wang C, Li W, Drabek D, Okba NM, van Haperen R, Osterhaus AD, van Kuppeveld FJ, et al. A human monoclonal antibody blocking SARS-CoV-2 infection. Nature Commu. 2020;11(1):1-6.

Cite this article as: Chatterjee $\mathrm{P}$, Mishra NP, Das A, Acharya S. A review on SARS-CoV2 drug regimens inferring plausible mechanisms to impede the viral propagation and cytokine storm. Int J Community Med Public Health 2021;8:2061-9. 